\title{
ĐẶC ĐIỂM HOẠT ĐỘNG TRONG NĂM CỦA ÁP THẦP ALEUT
}

\author{
Trần Đình Linh ${ }^{1}$, Phạm Minh Tiến ${ }^{1}$, Chu Thị Thu Hường ${ }^{1}$
}

Tóm tắt: Thông qua truờng độ cao địa thế vị và đường dòng trên các mưc đẳng áp chuẩn $1000 \mathrm{hPa}, 850 \mathrm{hPa}, 700 \mathrm{hPa}$ và $500 \mathrm{hPa}$ xây dưng tù số liệu tái phân tích ERA Interim trong thời kỳ 1981-2015, nghiên cưu đã xác định được đặc điểm hoạt động trong năm của áp thấp Aleut (AL). Kết quả cho thấy, trong thời gian hoạt động (tù̀ tháng 9 đến tháng 5), AL có sụ thay đổi cả về cuờng độ, vị trí và phạm vi hoạt động, trong đó có cuờng độ mạnh nhất trong các tháng chính đông. Hơn nũa, AL có cường độ mạnh thì vị trí và phạm vi hoạt động dịch chuyển và mở rộng về xích đạo đồng thời lấn sang phía tây. Theo chiều cao, AL suy yếu dần đồng thời có vị trí dịch dần sang phía tây. Kết quả nghiên cứu cũng cho thấy, rãnh Đông Á (EAT) chính là hệ thống được tạo ra tù sự suy yếu của $A L$ và EAT sâu hơn, có vị trí lệch tây hơn trung bình trong các tháng AL có cuờng độ mạnh, ngược lại, EAT nông hơn, có vị trí lệch đông hơn trong các tháng $A L$ có cuờng độ yếu. Về dòng gió ở trên cao phía sau EAT, kết quả cho thấy nó thiên nam hơn trong các tháng AL có cuờng độ mạnh và thiên đông hơn trong các tháng AL có cường độ yếu.

Từ khóa: Áp thấp Aleut, Dòng gió phía sau rãnh Đông Á, Rãnh Đông Á.

Ban Biên tập nhận bài: 08/10/2019 Ngày phản biện xong: 25/11/2019 Ngày đăng bài: 25/01/2020

\section{1. Đặt vấn đề}

AL là trung tâm áp thấp tồn tại gần quần đảo Aleut trên bản đồ khí áp mực biển trung bình, nó là một trong những trung tâm khí áp chính tác động đến hoàn lưu khí quyển của bán cầu Bắc. AL chủ yếu hoạt động mạnh trong các tháng mùa đông, trong mùa hè nó dịch chuyển về phía cực Bắc và hầu như không xuất hiện [1]. Với qui mô thời gian cỡ ngày, $\mathrm{AL}$ có vị trí thay đổi, thường có xu hướng dịch chuyển dần sang phía đông. Trong quá trình dịch chuyển của chuỗi xoáy thuận cận cực, các xoáy thuận đạt cường độ cực đại trên khu vực quần đảo Aleut [1]. AL cùng với áp thấp Iceland là hai trung tâm áp thấp trong hệ thống xoáy thuận ngoại nhiệt đới ở bán cầu Bắc [1-2].

AL là một áp thấp lạnh, một xoáy thuận front, đặc trưng khí quyển trong khu vực chi phối của áp thấp Aleut có sự tương phản lớn. Ở phía tây, phía bắc và phía đông khu vực trung tâm áp thấp là các khối không khí lạnh, còn ở phía nam là

${ }^{1}$ Khoa Khí tuợng Thủy văn - Đại học Tài nguyên và Môi trường Hà Nội

Email:tdlinh@hunre.edu.vn khối không khí nóng hơn. Từ phía tây bắc, dòng không khí lạnh từ vùng cực và từ áp cao lục địa Âu Á di chuyển tới giao tranh với dòng không khí nóng hơn ở phía nam hình thành front lạnh. Trong khi đó, từ phía nam, dòng không khí nóng từ áp cao cận nhiệt đới đi lên, giao tranh với không khí lạnh ở phía đông và đông bắc tạo nên front nóng [2].

$\mathrm{AL}$ ảnh hưởng lớn đến điều kiện thời tiết, khí hậu trên khu vực biển Bơ-rinh và bán đảo Alaska. Sự tăng cường của $\mathrm{AL}$ trong mùa đông và mùa xuân làm tăng bình lưu nóng và ẩm vào bán đảo Alaska làm gia tăng nhiệt độ trên khu vực tạo nên năm 1976 nóng nhất trong lịch sử ở Alaska trong giai đoạn trước năm 2001 [3]. Trên vùng biển Bơ-rinh, sự thay đổi vị trí của $\mathrm{AL}$ có ảnh hưởng lớn hơn sự thay đổi khí áp ở vùng trung tâm của nó. Khi AL tồn tại ở phía tây vùng biển này thì trên khu vực nóng hơn, ngược lại, khi AL bị phân tách thành hai trung tâm, một ở phía tây gần khu vực Đông Á và một ở phía đông gần bán đảo Alaska thì trên khu vực lạnh đi dị thường [4].

Cường độ $\mathrm{AL}$ có sự biến động từ năm này 
qua năm khác, nó biến động theo các dao động có chu kỳ khác nhau từ 3-7 năm, 8 -10 năm và 16-22 năm [5]. Sự thay đổi cường độ $\mathrm{AL}$ có liên quan chặt chẽ đến cả dao động Bắc Cực và hình thế Thái Bình Dương - Bắc Mỹ đồng thời chịu ảnh hưởng của nhiệt độ mặt nước biển trên khu vực xích đạo Thái Bình Dương và khu vực nhiệt đới Ấn Độ Dương [5].

AL có ảnh hưởng mạnh đến điều kiện thời tiết, khí hậu trên một vùng rộng lớn, từ Alaska, qua biển Bơ-rinh đến cả vùng Đông Á. Ở khu vực Đông Á, đã có nghiên cứu cho thấy vai trò của $\mathrm{AL}$ đến khu vực, một chỉ số đánh giá cường độ gió mùa mùa đông được xác định dựa trên gradient khí áp theo phương vĩ tuyến giữa áp cao Siberia và $\mathrm{AL}$ cho thấy phản ánh tốt đặc trưng của gió mùa mùa đông trên khu vực [6].

Ở Việt Nam, cho đến nay, nghiên cứu về $\mathrm{AL}$ chưa nhiều nhưng bước đầu cho thấy $\mathrm{AL}$ có ảnh hưởng nhiều đến thời tiết, khí hậu trong mùa đông ở Việt Nam [2,7]. AL ảnh hưởng đến thời gian hoạt động của gió mùa mùa đông ở Việt Nam, phạm vi AL trong tháng 10 mở rộng sang phía tây nhiều hơn trong các năm gió mùa mùa đông bắt đầu sớm và ngược lại thu hẹp về phía đông trong năm gió mùa mùa đông bắt đầu muộn [2].

Mặc dù đã có một số nghiên cứu về $\mathrm{AL}$ nhưng những hiểu biết về cấu trúc, qui luật hoạt động, sự thay đổi theo phương thẳng đứng của nó chưa đầy đủ. Chính vì vậy, nghiên cứu này sẽ tập trung xem xét về đặc điểm hoạt động, cấu trúc theo phương thẳng đứng của $\mathrm{AL}$ và bước đầu đưa ra nhận định về vai trò của $\mathrm{AL}$ đến sự xâm nhập lạnh vào Việt Nam.

\section{Số liệu và phương pháp nghiên cứu}

\subsection{Số liệu}

Nghiên cứu sử dụng số liệu tái phân tích ERA-Interim của Trung tâm khí tượng hạn vừa châu Âu ECMWF. Thời gian khai thác của số liệu là 35 năm trong giai đoạn từ 1981 đến 2015 với yếu tố được khai thác bao gồm: độ cao địa thế vị "z", tốc độ gió vĩ hướng "u" và tốc độ gió kinh hướng "v" tại các mực đẳng áp chuẩn $1000 \mathrm{hPa}, 850 \mathrm{hPa}, 700 \mathrm{hPa}$ và $500 \mathrm{hPa}$. Nguồn số liệu này được lựa chọn với độ phân giải $0,5 \times 0,5$ độ kinh vĩ bao trùm khu vực từ 0 đến 80 độ vĩ Bắc, 60 độ kinh Đông đến 100 độ kinh Tây.

\subsection{Phưong pháp nghiên cúu}

2.2.1. Phuoong pháp xác định đặc điểm hoạt động của áp thấp Aleut

Đặc điểm hoạt động trong các tháng của $\mathrm{AL}$ cũng như sự thay đổi theo phương thẳng đứng của nó được xem xét khi tiến hành phân tích trường độ cao địa thế vị trên các mực đẳng áp chuẩn $1000 \mathrm{hPa}, 850 \mathrm{hPa}, 700 \mathrm{hPa}$ và $500 \mathrm{hPa}$.

Các đặc trưng được xem xét bao gồm cường độ, vị trí tâm, phạm vi hoạt động, độ nghiêng theo phương thẳng đứng. Theo đó, vị trí tâm được xác định tương đối là tâm của đường đẳng địa thế vị khép kín trong cùng, phạm vi hoạt động là vùng chi phối của đường đẳng trị khép kín ngoài cùng nơi tiếp giáp với các hệ thống lân cận còn độ nghiêng của trục là trục nối vị trí tâm ở các mực đẳng áp.

Từ kết quả thu được, nghiên cứu đưa ra nhận định về sự thay đổi đặc điểm hoạt động của $\mathrm{AL}$ trong năm, bao gồm sự thay đổi về cường độ, vị trí tâm và phạm vi hoạt động.

2.2.2. Phưong pháp xác định sụ thay đổi của hoàn lưu trên khu vưc

Sự thay đổi hoàn lưu trên khu vực được xác định khi phân tích trường đường dòng tương ứng trong các tháng. Thông qua trường đường dòng, đặc điểm hoạt động của $\mathrm{AL}$ cũng được đánh giá bởi hoàn lưu xoáy thuận trên khu vực. Đặc biệt, đặc điểm của dòng gió trên cao khu vực lục địa Đông Á phía tây AL được phân tích kỹ lưỡng, dòng gió này chính là nhân tố có vai trò quyết định đến quá trình xâm nhập lạnh vào Việt Nam [8].

\section{Kết quả và thảo luận}

\section{1. Đăc điểm của áp thấp Aleut ở sát bề măt}

Kết quả phân tích cho thấy, tại mực $1000 \mathrm{hPa}$, AL hoạt động trong giai đoạn từ tháng 9 đến tháng 5 năm sau, trong các tháng chính hè (tháng 6 , tháng 7 , tháng 8 ), áp thấp này không còn phân tích được trên bản đồ trung bình (hình 1). Tháng 9 là tháng bắt đầu chu kỳ phát triển của AL (hình 1a). Kết quả trên hình 1 cho thấy, trong tháng này, $\mathrm{AL}$ có tâm ở vào khoảng $60 \mathrm{oN}, 165 \mathrm{oW}$ 
ngay trên vùng duyên hải bán đảo Alaska được bao quanh bởi đường đẳng địa thế vị 6 damđtv. Phạm vi của $\mathrm{AL}$ trong thời gian này còn khá nhỏ, khi nó chi phối trong khoảng 18 vĩ độ và 60 kinh độ quanh vùng trung tâm. Vùng chi phối này được bao quanh bởi đường đẳng địa thế vị 8damđtv khép kín.

Sang tháng 10 (hình $1 \mathrm{~b}$ ), AL phát triển mạnh lên khá nhiều so với trong tháng 9 . Địa thế vị vùng trung tâm giảm xuống, vị trí tâm dịch chuyển về gần xích đạo và phạm vi mở rộng hơn so với tháng trước. Tháng 10, tâm của AL được bao quanh bởi đường 4damdtv ở vào khoảng $58^{\circ} \mathrm{N}, 155^{\circ} \mathrm{W}$, phạm vi chi phối trong khoảng 27 vĩ độ, 115 kinh độ được bao quanh bởi đường đẳng trị 10damđtv khép kín.

Từ tháng 11, kết quả cho thấy $\mathrm{AL}$ có sự thay đổi mạnh mẽ cả về vị trí, cường độ và phạm vi hoạt động. Từ tháng 11 đến tháng 1 - tháng 2 , vị trí của $\mathrm{AL}$ đồng thời có sự dịch chuyển về gần xích đạo và dịch sang phía tây hơn. Trong thời gian này, cường độ $\mathrm{AL}$ mạnh lên nhanh đồng thời mở rộng phạm vi hoạt động về phía xích đạo và sang phía tây đến vùng Đông Á. Cụ thể, về vị trí và cường độ, trong tháng 11 (hình $1 \mathrm{c}), \mathrm{AL}$ có tâm ở vào khoảng $57^{\circ} \mathrm{N}, 160^{\circ} \mathrm{W}$ bao quanh bởi đường đẳng trị 2 damđtv, tháng 12 , vị trí trung tâm đã ở vào khoảng $53^{\circ} \mathrm{N}, 175^{\circ} \mathrm{W}$, còn đến tháng 1 , vị trí tâm ở vào khoảng $50 \mathrm{oN}, 175 \mathrm{oW}$ với đường đẳng trị -2 damđtv bao quanh. Về phạm vi chi phối, AL mới chi phối đến $40 \mathrm{oN}$ và mở rộng đến kinh tuyến $130^{\circ} \mathrm{E}$ trong tháng 11 , còn trong tháng 12 (hình $1 \mathrm{~d}$ ), phạm vi đã mở rộng về phía xích đạo đến vĩ tuyến $330 \mathrm{~N}$ và sang phía tây đến kinh tuyến $130^{\circ} \mathrm{E}$, tháng $1, \mathrm{AL}$ đã chi phối đến vĩ tuyến $30^{\circ} \mathrm{N}$, kinh tuyến $135^{\circ} \mathrm{W}$. So với trong tháng 1 (hình $1 \mathrm{e}$ ), AL trong tháng 2 có cường độ giảm đi nhưng không đáng kể còn về vị trí tâm và phạm vi hoạt động thì không thay đổi nhiều.

Từ tháng 3 đến tháng $5, \mathrm{AL}$ bước sang giai đoạn suy yếu nhanh về cường độ và thu hẹp về phạm vi hoạt động, đồng thời vị trí tâm cũng rút dần về phía cực và dịch dần sang phía đông. Thật vậy, trên khu vực giữa Thái Bình Dương (kinh tuyến $180^{\circ} \mathrm{E}$ ), phạm vi của $\mathrm{AL}$ thu hẹp đến khoảng $40 \mathrm{oN}$ trong tháng 3 , khoảng $47^{\circ} \mathrm{N}$ trong tháng 4 và khoảng $50^{\circ} \mathrm{N}$ trong tháng 5 . Cường độ AL suy yếu nhanh thể hiện qua sự gia tăng của địa thế vị vùng trung tâm. Trong tháng 3 , vùng trung tâm $\mathrm{AL}$ được bao quanh bởi đường đẳng trị $4 \mathrm{dam} đ t v$, đến tháng 4 giá trị này là 6 damđtv và tháng 5 chỉ còn 9 damđtv.

Như vậy, khi AL có cường độ mạnh lên thì vị trí tâm dịch gần về xích đạo và dịch sang phía tây, đồng thời phạm vi hoạt động mở rộng về phía xích đạo và lấn sang phía tây. Ngược lại, khi AL suy yếu thì vị trí tâm lùi về phía cực và sang phía đông, đồng thời thu hẹp phạm vi hoạt động về phía đông và về phía cực. Điều này gần như mâu thuẫn với một nhận định trước đây, rằng trong các năm $\mathrm{AL}$ mạnh thì có vị trí dịch sang phía đông, làm áp cao Seberia di chuyển lệch đông hơn dẫn đến nhiệt độ ở Việt Nam gia tăng hơn; ngược lại trong những năm $\mathrm{AL}$ yếu thì có phạm vi mở rộng sang phía tây làm áp cao Siberia di chuyển thiên nam hơn làm gia tăng số ngày rét đậm, rét hại ở Việt Nam [7].

Tiến hành phân tích trường đường dòng trên hình 1 chúng tôi nhận thấy, trong các tháng $\mathrm{AL}$ mạnh nhất, mở rộng phạm vi hoạt đông sang phía tây và về phía xích đạo nhất (các tháng 12 , $1,2)$ thì tâm áp cao Siebria nằm sâu trong lục địa và từ đây, không khí lạnh (KKL) xâm nhập vào Việt Nam qua lục địa Trung Quốc. Trong các tháng 3 , tháng 4 khi $\mathrm{AL}$ yếu và lùi sang phía đông thì trên lục địa châu Á hình thành tâm phụ của áp cao Siberia ở phía đông Trung Quốc, từ đây KKL vào Việt Nam sau khi vòng qua biển. Hơn nữa, thực tế cho thấy, trong các tháng chính đông, tần suất xâm nhập lạnh xuống Việt Nam nhiều làm nhiệt độ giảm mạnh và gia tăng số ngày rét đậm, rét hại trên khu vực. 


\section{BÀI BÁO KHOA HỌC}

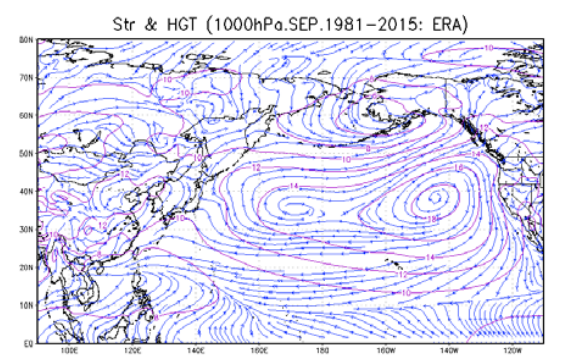

(a)

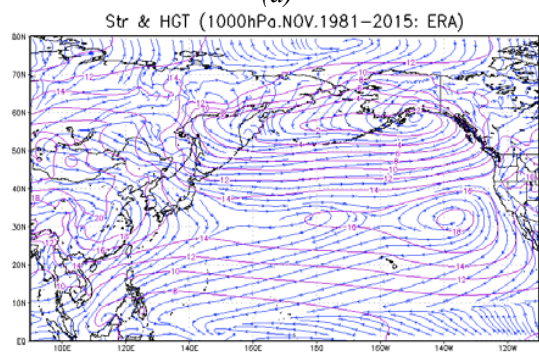

(c)

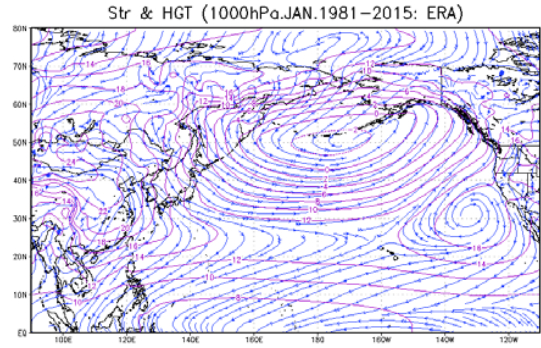

(e)

Str \& HGT (1000hPo.MAR.1981-2015: ERA)

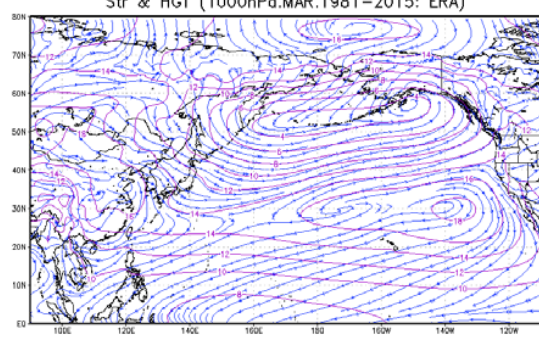

(g)

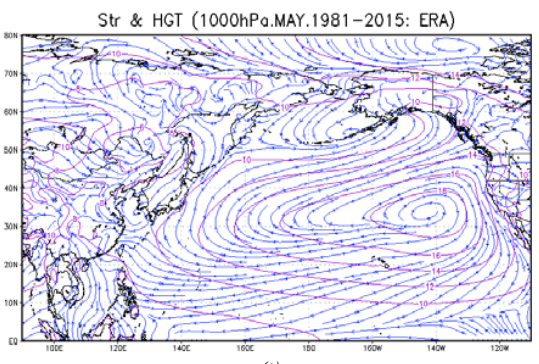

(i)

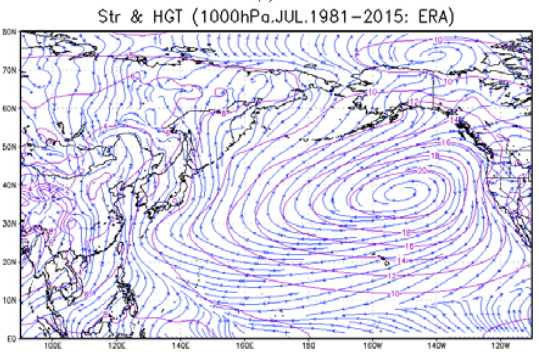

(k)

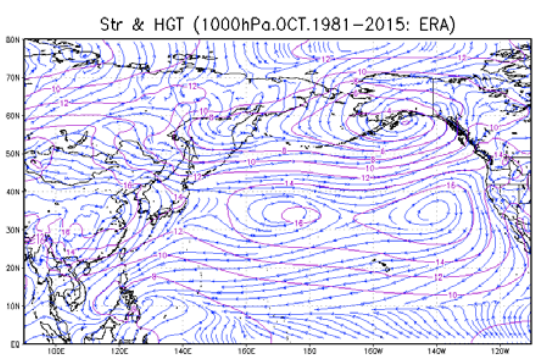

(b)

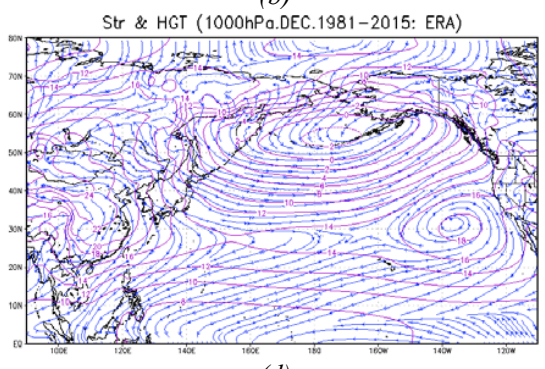

(d)

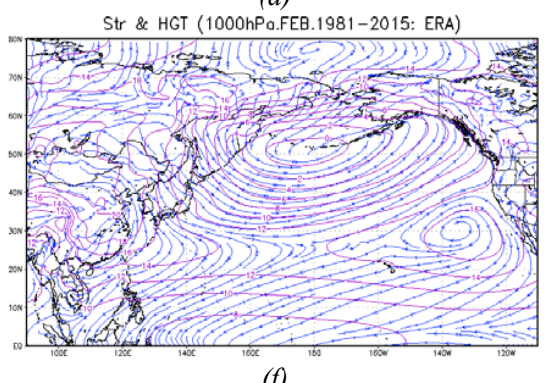

Str \& HGT (1000hPo.APR.1981-2015: ERA)

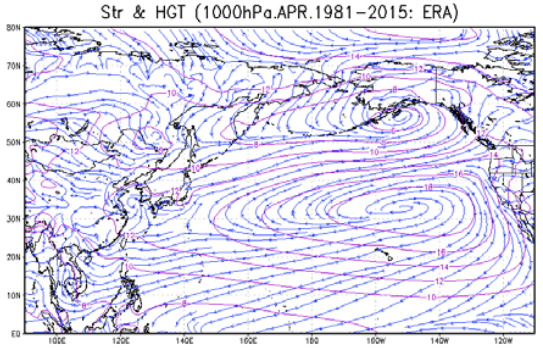

(h)

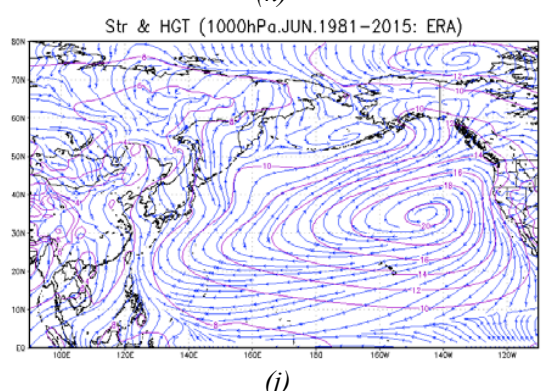

Str \& HGT (1000hPo.AUG.1981-2015: ERA)

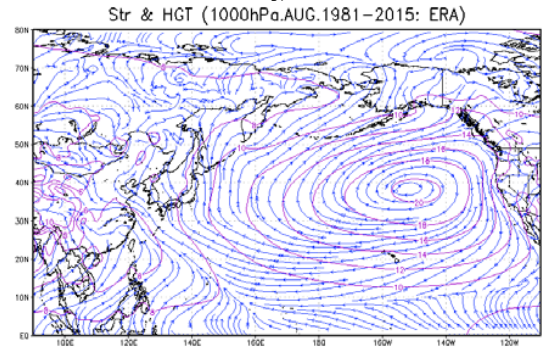

(l)

Hình 1. Đặc điểm trường độ cao địa thế vị (đường đẳng trị) và đương dòng (đường liền nét kèm mũi tên) ở mục 1000hPa trên khu vục áp thấp Aleut và lân cận các tháng trong năm 


\section{2. Đặc điểm của áp thấp Aleut ở các mục trên cao}

Kết qủa phân tích ở mực trên cho thấy khi $\mathrm{AL}$ mạnh thì khả năng làm giảm nhiệt độ và gia tăng số ngày rét đậm, rét hại ở miền Bắc Việt Nam. Để củng cố nhận định này, nghiên cứu tiến hành xem xét đặc điểm hoạt động của $\mathrm{AL}$ và đường dòng ở các mực $850 \mathrm{hPa}, 700 \mathrm{hPa}$ và $500 \mathrm{hPa}$ kết quả cho thấy nhận định trên hoàn toàn có cơ sở.

Thật vậy, khi xem xét đặc điểm hoạt động của $\mathrm{AL}$ ở mực $850 \mathrm{hPa}$ và các mực $700 \mathrm{hPa}, 500 \mathrm{hPa}$ (hình 2) cũng cho thấy trong các tháng $\mathrm{AL}$ có cường độ mạnh có tâm lệch tây và phạm vi hoạt động mở rộng sang phía tây đồng thời điều kiện hoàn lưu thuận lợi cho sự xâm nhập lạnh xuống Việt Nam. Ngược lại, trong các tháng AL yếu thì phạm vi hoạt động thu hẹp về phía đông, hoàn lưu trên cao có xu hướng làm KKL ở tầng thấp di chuyển lệch đông. Kết quả phân tích cũng cho thấy AL suy yếu, vị trí tâm lệch dần sang phía tây đồng thời phạm vi thu hẹp nhanh khi lên cao.

Trong tất cả các tháng AL hoạt động (tháng 9 đến tháng 5), ở mực $850 \mathrm{hPa}$, mặc dù không đưa hình vẽ vào trong nghiên cứu này nhưng khi tiến hành phân tích cho thấy $\mathrm{AL}$ đều được thể hiện rõ thông qua cả trường độ cao địa thế vị và trường đường dòng. Tất cả các tháng, trường độ cao địa thế vị cho đều có đường đẳng trị khép kín bao quanh khu vực tâm còn trường đường dòng cho thấy hoàn lưu xoáy thuận hội tụ vào tâm AL. Về vị trí tâm, ở mực này có sự dịch chuyển sang phía tây hơn so với ở mực $1000 \mathrm{hPa}$.

Mực $700 \mathrm{hPa}$, thông qua trường độ cao địa thế vị, $\mathrm{AL}$ chỉ được thể hiện tâm áp thấp rõ ràng bởi các đường đẳng trị khép kín quanh tâm trong các tháng $\mathrm{AL}$ có cường độ mạnh nhất (tháng 12 , tháng 1 , tháng 2 ) còn các tháng còn lại chỉ còn một rãnh áp thấp trên khu vực Đông Á, rãnh thấp này chính là rãnh Đông Á (East Asia Trough EAT). Vị trí EAT trong các tháng mà ở các mực dưới $\mathrm{AL}$ có cường độ mạnh hơn cũng ở phía tây hơn so với các tháng AL yếu, tương quan vị trí này tương tự như tương quan vị trí tâm $\mathrm{AL}$ ở cá mực dưới. Về trường đường dòng, ở mực này, dòng gió trên khu vực lực địa Đông Á phía tây của AL hay EAT thiên nam hơn trong các tháng $12,1,2$ và thiên đông hơn trong các tháng còn lại. Điều này hoàn toàn phù hợp với nhận định ở trên.

Ở mực $500 \mathrm{hPa}$, trong tất cả các tháng, chỉ còn phân tích được EAT mà không còn phân tích được AL. Kết quả cũng cho thấy EAT sâu hơn trong các tháng chính đông và nông hơn trong các tháng khác. Đối với trường đường dòng, chỉ có các tháng 12, 1, 2 phân tích được tâm xoáy thuận còn các tháng khác trên khu vực chỉ thể hiện hoàn lưu dạng rãnh trong đới gió tây. Cũng tương tự như ở mực $700 \mathrm{hPa}$, ở mực này, dòng gió phía sau EAT thiên nam hơn trong các tháng chính đông, thiên đông hơn trong các tháng đầu và cuối đông. Đặc điểm này được thể hiện ở mực $500 \mathrm{hPa}$ rõ ràng hơn so với mực $700 \mathrm{hPa}$.

Kết quả về đặc điểm của EAT và dòng gió phía sau EAT ở trên là phù hợp với những hiểu biết trước đây về vai trò của hệ thống trên cao đối với quá trình xâm nhập lạnh vào Việt Nam, cụ thể, khi EAT sâu hơn và có vị trí trên lục địa Đông Á thì dòng gió phía sau EAT thiên nam hơn tác động làm KKL ở tầng thấp di chuyển qua lục địa vào Việt Nam còn khi EAT nông, dòng gió phía sau EAT thiên đông hơn làm $\mathrm{KKL}$ di chuyển lệch đông $[8,9]$. 


\section{BÀI BÁO KHOA HỌC}

Str \& HGT (700hPo.SEP.1981-2015: ERA)

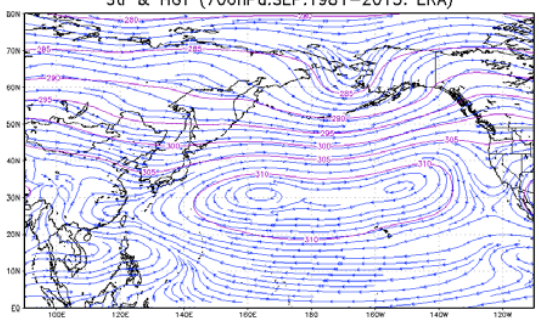

(a)

Str \& HGT (700hPo.OCT.1981-2015: ERA)

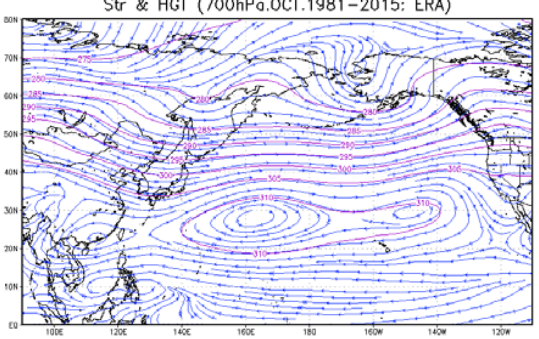

(c)

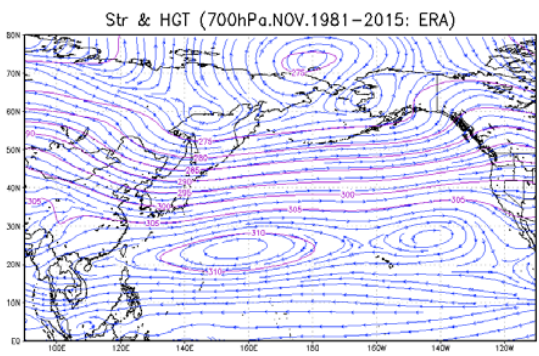

(e)

Str \& HGT (700hPo.DEC.1981-2015: ERA)

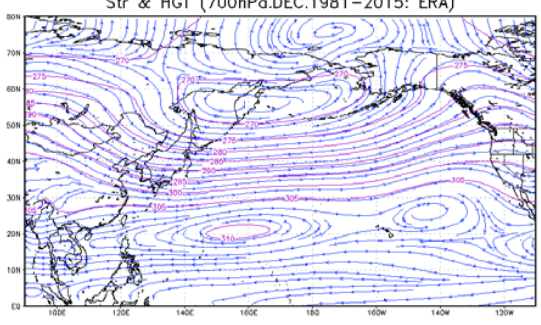

(g)

Str \& HGT (700hPo.JAN.1981-2015: ERA)

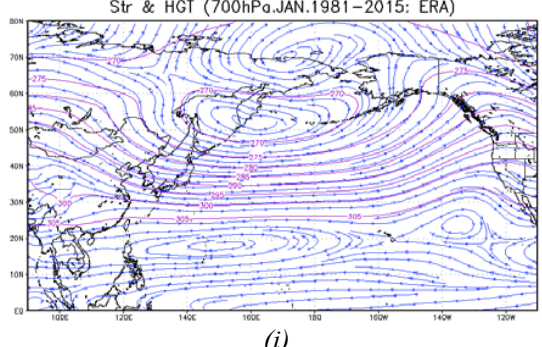

Str \& HGT (700hPa.FEB.1981-2015: ERA)

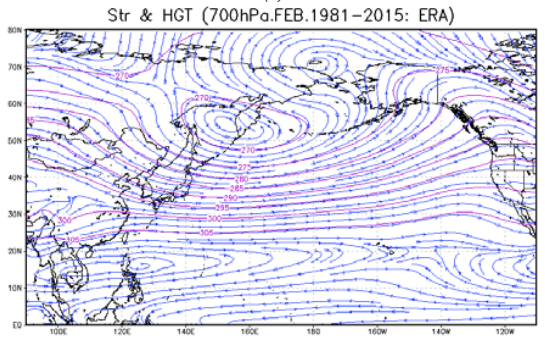

(k)

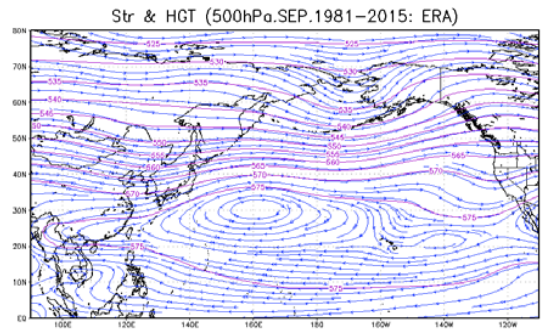

(b)

Str \& HGT (500hPo.OCT.1981-2015: ERA)
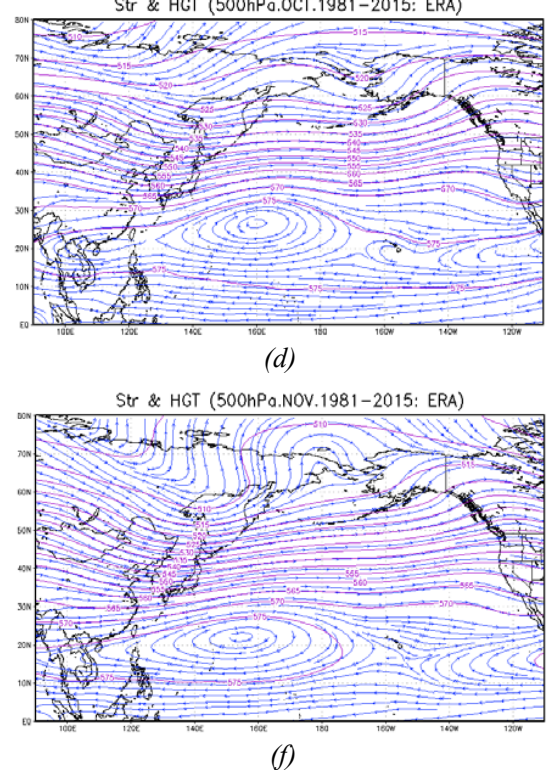

Str \& HGT (500hPo.DEC.1981-2015: ERA)

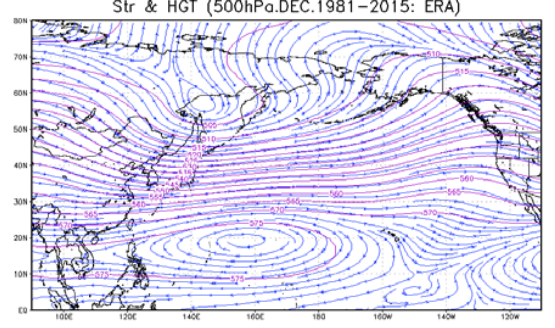

(h)

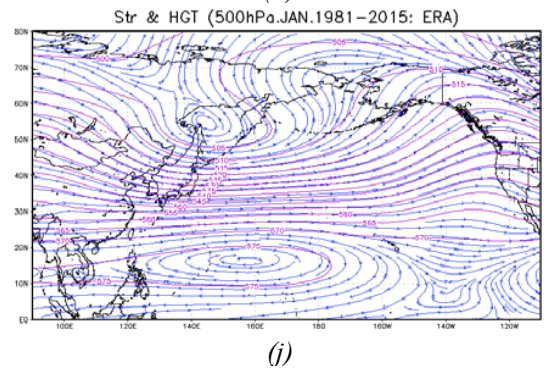

Str \& HGT (500hPa.FEB.1981-2015: ERA)

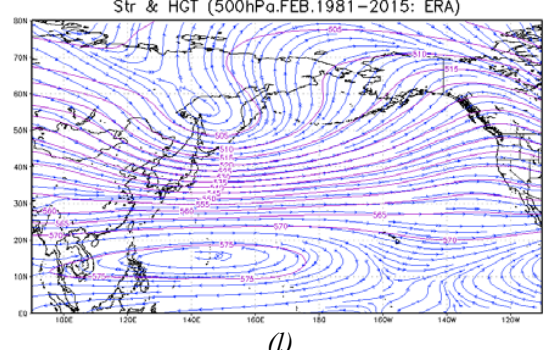




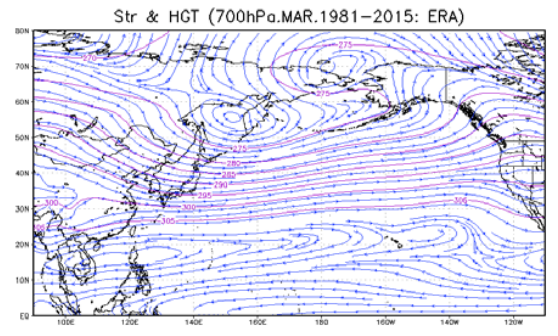

(m)

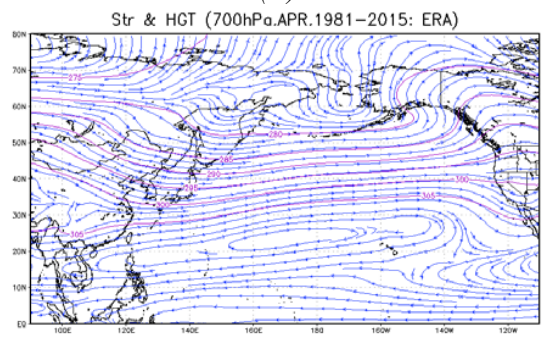

(o)

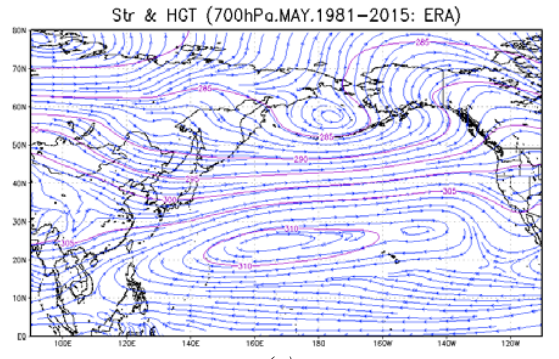

(q)

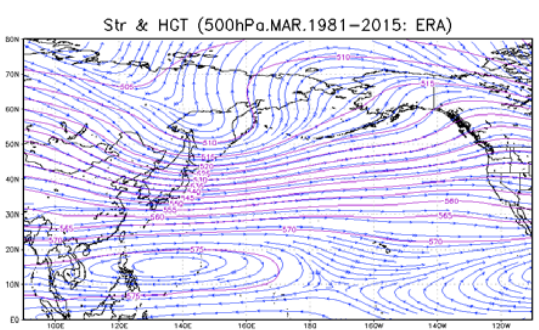

(n)

Str \& HGT (500hPo.APR.1981-2015: ERA)

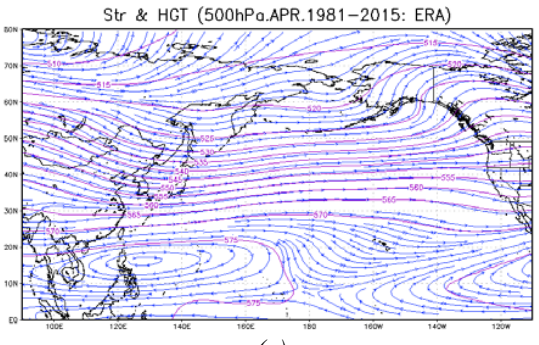

(p)

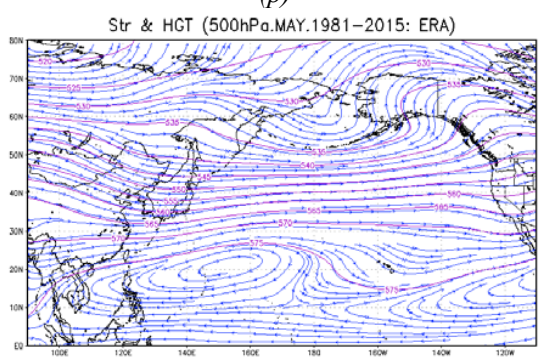

(r)

Hình 2. Tưong tụ hình 1 nhưng ở mục 700hPa (trái) và mục 500hPa (phải) trong các tháng áp thấp Aleut hoạt động

\section{Kết luận}

Qua phân tích đặc điểm hoạt động của áp thấp Aleut trong thời kỳ 35 năm từ 1981 đến 2015, nghiên cứu rút ra một số kết luận sau:

1. Áp thấp Aleut là một trung tâm khí áp tầm trung, bán vĩnh cữu hoạt động trên khu vực quần đảo Aleut ổn định trong các mùa đông và đầu hè của bán cầu Bắc (từ tháng 9 đến tháng 5 ).

2. Cường độ của áp thấp Aleut thay đổi trong suốt thời gian hoạt động. Trong các tháng chính đông, áp thấp Aleut có cường độ mạnh nhất trong năm.

3. Vị trí tâm, phạm vi hoạt động của áp thấp Aleut thay đổi theo cường độ của nó. Khi có cường độ mạnh, áp thấp Aleut có tâm ở gần xích đạo và dịch dần sang phía tây đồng thời mở rộng phạm vi hoạt động về phía xích đạo và sang phía tây hơn.

4. Theo chiều cao, áp thấp Aleut suy yếu dần đồng thời có vị trí tâm dịch dần sang phía tây. Đến mực $700 \mathrm{hPa}$, áp thấp Aleut thông thường chỉ còn là một rãnh áp thấp, chỉ khi có cường độ mạnh mới thể hiện dưới dạng một vùng áp thấp.

5. Rãnh Đông Á là hệ thống khí áp tạo do áp thấp Aleut suy yếu khi lên cao. Rãnh Đông Á sâu hơn và có vị trí lệch tây hơn trung bình trong các tháng áp thấp Aleut có cường độ mạnh, ngược lại, rãnh Đông Á nông hơn và có vị trí lệch đông hơn trong các tháng áp thấp Aleut có cường độ yếu.

6. Dòng gió ở trên cao phía sau rãnh Đông Á thiên nam hơn trong các tháng áp thấp Aleut có cường độ mạnh và thiên đông hơn trong các tháng áp thấp Aleut có cường độ yếu. 


\section{BÀI BÁO KHOA HỌC}

\section{Tài liệu tham khảo}

1. American Meteorologycal Society (2012), Atletian Low, Meteorology Glossary http://glossary.ametsoc.org/wiki/Aleutian_low.

2. Chu Thị Thu Hường và cs (2018), Nghiên cứu sự dịch chuyển mùa của các hệ thống gió mùa và ảnh hưởng của nó đến sự biến động thời tiết trên khu vực Việt Nam. Báo cáo tổng kết đề tài nghiên cứu khoa học cấp Bộ.

3. Hartmann, B., Wendler, G., (2005), The significance of the 1976 Pacific climate shift in the climatology of Alaska. Journal Climate, 18, 4824-4839.

4. Rodionov, S.N., Overland, J.V., Bond, N.A., (2005), The Aletian low and Winter climatic conditions in the Bering sea, Part 1: Classification. Journal climate, 18, 160-177.

5. Chen, Y., Zhai, P., (2011), Interannual to decadal variability of winter Aleutian low intensity during 1900-2004. ACTA Meteorologica Sinica, 25 (6), 710-724.

6. D’Arrigo, R., Wilson, R., Panagiotopoulos, F., Wu, B., (2005), On the long-term interannual variability of the east Asian winter monsoon. Geophysical Research Letters, 32, L21706, Doi:10.1029/2005GL023235.

7. Nguyễn Viết Lành, Phạm Minh Tiến (2016), Nghiên cứu mối quan hệ giữa xâm nhập lạnh xuống Việt Nam và áp thấp Aleut. Tạp chí Khoa học ĐHQGHN: Các khoa học Trái đất và Môi trường, 32 (3S), 148-152.

8. Trần Việt Liễn (2010), Giáo trình Khí hậu Việt Nam. Trường Đại học Tài nguyên và Môi trường.

9. Thái Thị Thanh Minh, Trần Thị Huyền Trang (2015), Rãnh Đông Á và sự biến đổi của nó qua những thập kỷ gần đây. Tạp chí Khí tượng Thủy văn, 655, 23-30.

\section{CHARACTERISTICS OF THE ALEUTIAN LOW Tran Dinh Linh', Pham Minh Tien', Chu Thi Thu Huong ${ }^{1}$ \\ ${ }^{1}$ Faculty of Meteorology and Hydrology, \\ Hanoi University of Natural Resources and Environment}

Abstract: From the geopotential high and stream lines fields on four standard iso-metric pressure levels of $1000 \mathrm{hPa}, 850 \mathrm{hPa}, 700 \mathrm{hPa}$ and $500 \mathrm{hPa}$ built from ERA Interim re-analysis data in the 1981-2015 period, this study has identified characteristics of the Aleutian low (AL). The results show, from September to May, AL has changed in all of intensity, location and scale of activities. AL is strongest in the winter months. Moreover, when AL has strong intensity, the location of it's center move to the equator and encroach to the west and the scale also expand towark the equator and to the East Asia continent. According to the height, AL gradually weaken and are located to the west. The results also show that the East Asia Trough (EAT) is the system created from the weakening of AL. EAT is stronger, deviating more west than average in the months when AL's intensity is strong. Inconstrast, EAT is weaker and move to eastwark in the months when AL's intensity is weaker. Regarding to the wind at high levels behind the EAT, the results show that it is more southernly in the months when has strong intensity and more easterly in the months when weak intensity of AL's intensity.

Keywords: Aleutian Low, East Asia Trough, the Wind behind the East Asia Trough. 